\title{
Intravascular haemolysis in the recreational runner
}

\author{
Ronald W. Deitrick PhD, FACSM \\ Department of Health, Physical Education and Recreation, California State Polytechnic University, Pomona, \\ California 91768-4079, USA
}

\begin{abstract}
Intravascular haemolysis has been found to result from prolonged endurance competition, rigorous military training and participation in impact sports. Haematological research involving the recreational runner is sparse. Recreational runners frequently vary their training to avoid monotony and improve endurance capacity. This study investigated the haematological effects of a typical day of increased distance training in $\mathbf{1 5}$ male recreational runners $\left(62.4(3.1) \mathrm{ml} \mathrm{kg}^{-1} \min ^{-1}\right.$ treadmill $\dot{V}_{\mathrm{O}_{2} \max }$ 44.6(8.4) km per week training (mean(s.d.)). Venous blood samples were collected before, immediately after, 1 day, 4 days, and 10 days after a 13-km training run (about twice the subjects' typical running distance) and analysed for changes in bilirubin, serum potassium, haematocrit, haemoglobin, red blood cell count, haptoglobin, poikilocytosis and reticulocytosis. Urine samples were collected at the same times as the blood samples and analysed for urobilinogen. Significant $(P<0.05) 1$-day and 4-day decreases in mean haemoglobin, red blood cell count, and haptoglobin values, compared to before training venous blood values and significant $(P<0.05)$ post-training increases in bilirubin, serum potassium, urobilinogen and poikilocytosis provided evidence for increased intravascular haemolysis. After 10 days the values for haematocrit, bilirubin, serum potassium, red blood cell count, urobilinogen and poikilocytosis were not significantly $(P>0.05)$ different from pre-training values while haemoglobin remained significantly $(P<0.05)$ lower, exhibiting a constant but not significant increase over the period from $\mathbf{1}$ to $\mathbf{1 0}$ days. The results indicate that mild intravascular 'footstrike' haemolysis can occur in the recreational runner when typical training distance is increased. This condition appears to be transient and benign.
\end{abstract}

Keywords: Running, training effects, sports haematology, endurance exercise

Sports anaemia is a term which has been used to describe both pseudodilutional anaemia and the true anaemias of athletes. Pseudodilutional anaemia is a normally occurring and beneficial adaptation to endurance training which is characterized by an overcompensation, that is expansion, of plasma volume. The two most common causes of true anaemia in athletes are iron deficiency and intravas-

Address for correspondence: Ronald W. Deitrick, HPER

Department - Sportsmedicine Research Clinic, California State

Polytechnic University, 3801 West Temple Avenue, Pomona, CA

91768-4079, USA

(C) 1991 Butterworth-Heinemann Ltd

0306-3674/91/040183-05 cular ('footstrike') haemolysis ${ }^{1}$ which results in urinary loss of iron. Increased intravascular haemolysis has been observed to occur as a result of rigorous military training ${ }^{2}$ and from participation in impact sports ${ }^{3,4}$. It has also been recognized in unfit individuals suddenly subjected to a strenuous bout of exercise ${ }^{5}$ and in highly trained endurance athletes after marathon ${ }^{6}$ and ultra-endurance competition ${ }^{7,8}$. More recently, an intensive training programme consisting of vigorous isometric and isotonic exercises ${ }^{9}$ and high amounts of training in well-trained middle- and long-distance runners ${ }^{10}$ has been investigated and shows evidence of increased intravascular haemolysis. No evidence exists regarding the haematological effect of a typical increased daily training distance on the moderately trained, 'recreational', endurance runner.

Despite some newer forms of aerobic exercise such as aerobic dance and cross-training sports like the triathlon, running continues to be extremely popular. It is estimated that there are more than 30 million runners in the USA alone. The great majority of these individuals are not competitive runners. However, they do alter their training so as to avoid monotony and to improve their cardiorespiratory endurance capacity. The haemolytic effects of such changes in training in the recreational runner remain largely unexplored.

The purpose of this study was to examine the effect of increasing the distance of a daily training run, by a typical amount, on the development of intravascular haemolysis in moderately trained endurance runners. Haematological, morphological and urinalysis measures were selected to study the effects and time course changes during recovery.

\section{Patients and methods}

Fifteen endurance trained Caucasian men volunteered to participate in this study. Each subject had been running $32-56 \mathrm{~km}$ per week and possessed a maximal oxygen consumption $\left(\dot{V}_{\mathrm{O}_{2} \text { max }}\right)$ in the range of $55-65 \mathrm{ml} \mathrm{kg}^{-1} \mathrm{~min}^{-1}$. All testing procedures were carefully explained and each subject signed an informed consent form before participating. A training questionnaire was also completed at this time. Percentage body fat was determined as described by Zuti and Golding ${ }^{11}$. Table 1 displays the physical and physiological characteristics of the subjects while Table 2 presents their training characteristics. 
Table 1. Physical and physiological characteristics of male recreational runners

\begin{tabular}{lcc}
\hline Variables & Mean(s.d.) & Range \\
\hline Age (years) & $27.8(6.3)$ & $19-40$ \\
Height $(\mathrm{cm})$ & $172.5(23.8)$ & $165-190$ \\
Weight $(\mathrm{kg})$ & $70.6(7.3)$ & $60.5-85$ \\
Body fat $(\%)$ & $12.1(3.7)$ & $7.4-20.3$ \\
$\dot{V O}_{2 \max }\left(\mathrm{ml} \mathrm{kg}^{-1} \mathrm{~min}^{-1}\right)$ & $62.4(3.1)$ & $55.2-65.6$ \\
\hline$n=15$ & & \\
& &
\end{tabular}

Table 2. Training characteristics and environmental conditions for $13-\mathrm{km}$ training run

\begin{tabular}{lcc}
\hline Variables & Mean $(\mathrm{s.d.})$ & Range \\
\hline Weekly distance $(\mathrm{km})$ & $44.6(8.4)$ & $32-56$ \\
Distance per run $(\mathrm{km})$ & $8.9(1.6)$ & $6.4-11.2$ \\
Frequency per week & $4.7(0.9)$ & $3-6$ \\
Time for training run $(\min : \mathrm{s})$ & $55: 19(3: 55)$ & $50: 22-62: 30$ \\
Ambient temperature $\left({ }^{\circ} \mathrm{C}\right)$ & $22.3(1.1)$ & - \\
Relative humidity $(\%)$ & $54(4.3)$ & - \\
\hline
\end{tabular}

$n=15$

To determine $\dot{V}_{\mathrm{O}_{2 \max }}$ each subject underwent a continuous, progressive, multistage treadmill test. The protocol consisted of a brief warm-up followed by an initial exercise intensity of $188 \mathrm{~m} \mathrm{~min}^{-1}$ at a $4 \%$ grade (this represents a treadmill elevation of four vertical units for every 100 horizontal units) with a $2.5 \%$ increase in grade every $2 \mathrm{~min}$ thereafter, while keeping speed constant. Verbal encouragement was given throughout the test, especially at the highest levels of exercise intensity. Oxygen consumption was determined at 30-s intervals using a Beckman Metabolic Cart (MMCI, Beckman Instruments, Brea, California, USA). Criteria for $\dot{V}_{\mathrm{O}_{2}}$ max included a plateau in oxygen consumption (less than $2 \mathrm{ml} \mathrm{kg}^{-1} \mathrm{~min}^{-1}$ increase with a further increase in workload), a respiratory exchange ratio greater than 1.1 , and approximation (within ten beats per minute) of age predicted maximum heart rate. With a majority of the criteria satisfied, the highest rate of oxygen consumption achieved was recorded as $\dot{V}_{O_{2}}$ max Heart rate was monitored continuously by an electrocardiogram using a CM5 lead placement (negative electrode on manubrium, positive electrode on 5th intercostal space, left anterior axillary line).

After treadmill testing, three separate days were scheduled for the 13- $\mathrm{km}$ run with the time of day (mid-morning) held constant. The course was flat and every subject ran it once within a week. The course surface comprised a mixture of dirt and gravel (the soft shoulder of a road) with occasional stretches of blacktop. Seven of the 15 subjects ran on the first scheduled day, four ran on the second day and four ran on the last day. The subjects were instructed not to run longer than their average daily training distance for at least 4 days before the 13- $\mathrm{km}$ run while maintaining average daily training intensity, and also to resume typical training distances after the 1-day blood draw but not to do any longer or more intense runs than they would normally do until after the final blood draw. The intention was to observe the selected variables during the normal course of training in a group of recreational runners with a minimum of experimental interference.

On the day of the run, subjects were instructed to run the $13 \mathrm{~km}$ as though it was a hard training run. They were reminded not to compete with each other but rather to run at a training pace that was typical for them, for this distance. Subjects ran on the same day only for ease of post-run data collection. Each subject agreed at the end of the $13 \mathrm{~km}$ that his effort was similar to a typical hard training run as indicated on the training questionnaire. The environmental conditions and times for the training run are shown in Table 2.

With the subject seated, fasting venous blood samples ( $12 \mathrm{ml}$ total per draw) were collected by an experienced certified phlebotomist for analyses before the increased distance training run and at selected times after the run (within $1 \mathrm{~h}, 1$ day, 4 days and 10 days). The pre-training run values were considered to be representative of typical training status. Extreme care was taken during the venepuncture to avoid the possibility of any haemolysis from the blood draw itself. All samples were transported on ice to a nationally accredited (Joint Commission on Accreditation for Hospitals) clinical laboratory. Using anti-coagulated ethylene diamine tetra-acetic acid (EDTA) blood, the haematological assays were performed within $4 \mathrm{~h}$ after collection by a registered American Society of Clinical Pathologists (ASCP) medical technologist on a J.T. Baker Model 500A haematology analyser (Serono-Baker Diagnostics, Allentown, Pennsylvania, USA) which had been calibrated immediately before assessment.

Serum potassium, total lactate dehydrogenase (LDH), and bilirubin concentrations were analysed on a Technicon SMA/20 automated analyser (Technicon Instruments, Tarrytown, New York, USA). The potassium method was a direct potentiometric procedure for the quantitative measurement of potassium in buffered serum ${ }^{12}$. The potassium ion-selective electrode responds to potassium ions according to the Nernst equation. Total LDH determination was based on methods and modifications previously described ${ }^{13}$. The total bilirubin method was a quantitative colorimetric procedure ${ }^{14}$. Assays for haptoglobin were determined using M-Partigen haptoglobin kits containing radial immunodiffusion plates obtained from Calbiochem-Behring Corporation (Behring Diagnostics, Somerville, New Jersey, USA). All procedures and calculations were conducted in accordance with the instructions accompanying the kits and met all the criteria specified therein.

All urines were collected in standard urinalysis specimen containers and analysed immediately after collection. Urobilinogen was determined on the urine specimens using Ames multistix reagent strips (Miles, Diagnostics Division, Elkhart, Indiana, USA) and following the accompanying instructions. Using a Wright's stained blood smear of anticoagulated blood (EDTA as the anticoagulant), poikilocytosis was observed and rated $0,+1,+2,+3$ or +4 
following the standard procedure employed by the medical laboratory responsible for the morphological evaluation. Reticulocytosis was measured microscopically using a drop of new methylene blue anticoagulated blood mixture. Reticulocytes were enumerated in red blood cell counts of a thousand and expressed as a percentage. All blood and urine analyses were performed by registered (ASCP) medical technologists who were unaware of the purpose of the study.

A single-group repeated-measures research design was used for this study with statistical significance determined by analysis of variance. The repeated measures research design allows for the highest degree of comparability among subjects (since subjects serve as their own controls) and is the dictated design when the study involves measuring the same group of subjects over time to assess effects which develop with the passage of time ${ }^{15}$. Additionally, the repeated measures design provides a means of increasing the number of subjects in a study. One limitation of such a study design is the possibility of carry-over effects. This was perhaps a limitation in this study since the subjects were permitted to resume normal training after the 1-day blood draw. However, the study was designed to provide for an assessment of the haematological effects of a typical increase in training distance in a realistic training setting. This necessitated the resumption of training following the 13-km run. Using selected orthogonal contrasts, post hoc analyses were conducted to probe for significant differences when indicated. Results were judged significant where $P<0.05$.

\section{Results}

The endurance runners in this study averaged $44.6 \mathrm{~km}$ of running per week while training on average, 4.7 times per week and $8.9 \mathrm{~km}$ per run (Table 2). The mean maximal oxygen consumption value of $62.4 \mathrm{ml} \mathrm{kg}^{-1} \mathrm{~min}^{-1}$ for this group is greater than the typical $\dot{V O}_{2}$ max value of $39.1 \mathrm{ml} \mathrm{kg}^{-1} \mathrm{~min}^{-1}$ reported for individuals of this age and sex ${ }^{16}$; lower than the value of $70-85 \mathrm{ml} \mathrm{kg}^{-1} \mathrm{~min}^{-1}$ reported for elite male endurance runners ${ }^{17}$; and similar to the $60.6 \mathrm{ml} \mathrm{kg}^{-1} \mathrm{~min}^{-1}$ reported for other male recreational runners ${ }^{18}$. In addition, these runners were leaner than the average man for their age group, $12.1 \%$ versus $20.1 \%$ body fat ${ }^{16}$ and not as lean as high calibre endurance athletes: $12.1 \%$ versus $5-8 \%$ body fat ${ }^{17}$.

Only two of the runners had run in a race (both $10 \mathrm{~km}$ ) during the 6 months before the study, and none had ever run a half or full marathon. The 13-km training run represented the average distance of what the runners in this study currently used as an increased, once a week, training distance, as stated on the training questionnaire. The range of distances used for this purpose varied from $9.6 \mathrm{~km}$ to $16 \mathrm{~km}$ with about half of the study group reporting $13 \mathrm{~km}$. Evidence for the increased effort required to complete this increased training distance can be seen in the significantly $(P<0.05)$ elevated LDH levels as measured within $1 \mathrm{~h}$ after the training run and compared to the pre-training run values (Table 3 ).

The mean haematological values for haematocrit, haemoglobin, red blood cell count, haptoglobin and mean cell volume for each of the measurement time periods assessed are shown in Table 3. The haematocrit and red blood cell values increased significantly $1 \mathrm{~h}$ after the increased distance training run when compared to their respective pre-training run values, after which time both decreased significantly; that is, 1-day values were significantly lower than 1-h post-training values for these two variables. Red blood cell values were significantly lower than pre-training run values when measured 1 day and 4 days afterwards. The haemoglobin concentration measured 1 day after the increased distance training run was significantly decreased from the pre-training run values and remained so when measured 4 days and 10 days after the run.

Haptoglobin was significantly lower 1 day and 4 days after the increased distance training run but returned to pre-training run values by the tenth day.

Table 3. Blood and urine responses to increased distance training run*

\begin{tabular}{|c|c|c|c|c|c|}
\hline \multirow[t]{2}{*}{ Variables } & \multirow{2}{*}{$\begin{array}{l}\text { Pre-training } \\
\text { run }\end{array}$} & \multicolumn{4}{|c|}{ Post-training run } \\
\hline & & $1 h$ & 1 day & 4 days & 10 days \\
\hline \multicolumn{6}{|l|}{ Clinical chemistry } \\
\hline Lactate dehydrogenase $\left(\mathrm{UI}^{-1}\right)$ & $190.7(32.1)$ & $236.8(43.4) \dagger$ & $207(30.8)$ & 192.2(37.1) & $195.4(32.9)$ \\
\hline Bilirubin (mg dl $\left.{ }^{-1}\right)$ & $0.6(0.1)$ & $0.8(0.2) \dagger$ & $0.7(0.2)$ & $0.6(0.2)$ & $0.6(0.1)$ \\
\hline Serum $K^{+}\left(\right.$meq $\left.I^{-1}\right)$ & $4.5(0.4)$ & $4.8(0.6) \dagger$ & $4.6(0.6)$ & $4.3(0.4)$ & $4.4(0.4)$ \\
\hline \multicolumn{6}{|l|}{ Haematology } \\
\hline Haematocrit (\%) & 44.5(1.7) & 45.9(2.6)t & 43.6(1.4)‡ & $44.2(1.7)$ & $44.5(1.6)$ \\
\hline Haemoglobin $\left(\mathrm{g} \mathrm{dl}^{-1}\right)$ & $15.6(0.5)$ & $15.8(0.7)$ & 15.1(0.3)t‡ & $15.0(0.4)+$ & $15.2(0.5)+$ \\
\hline Red blood cell $\left(10^{6} \mathrm{~mm}^{-3}\right)$ & $5.02(0.26)$ & $5.17(0.31) \dagger$ & 4.86(0.19)†‡ & $4.88(0.34) \dagger$ & $4.95(0.29)$ \\
\hline Haptoglobin (g $100 \mathrm{ml}^{-1}$ ) & 91.9(69.1) & $80.4(75.1)$ & $66(65.8)+$ & $59.5(52.9) t$ & $81.8(63)$ \\
\hline Mean cell volume $\left(\mu \mathrm{m}^{3}\right)$ & $89(3.9)$ & 89.3(3.5) & $89.6(2.8)$ & $90.6(3.9)$ & $89.8(3.2)$ \\
\hline \multicolumn{6}{|l|}{ Urinalysis } \\
\hline Urobilinogen (Ehrlich units $\mathrm{dl}^{-1}$ ) & $0.1(0)$ & $0.8(0.4) t$ & $0.4(0.4)+\ddagger$ & $0.1(0) \S$ & $0.1(0.2) \S$ \\
\hline \multicolumn{6}{|l|}{ Morphological } \\
\hline Poikilocytosis $(0,+1,+2,+3$ or +4$)$ & 0 & $0.33(0.48) \dagger$ & $0.4(0.5) t$ & $0.4(0.5) \dagger$ & $0.1(0.2)$ \\
\hline Reticulocytosis (\%) & $0.55(0.27)$ & $0.56(0.21)$ & $0.61(0.28)$ & $0.71(0.23)$ & $0.64(0.15)$ \\
\hline
\end{tabular}

* Values are means(s.d.); $n=15 ;+$ significantly $(P<0.05)$ different from pre-training run; $\neq$ significantly $(P<0.05)$ different from $1 \mathrm{~h}$ after the training run; $\S$ significantly $(P<0.05)$ different from 1 day after the training run 
Serum potassium and bilirubin were initially significantly elevated, as measured within $1 \mathrm{~h}$ after the training run, but were not significantly different from pre-training run values when measured thereafter (Table 3). LDH, haptoglobin and serum potassium were the only variables outside the normal range during any of the measurement times, and all of the variables selected for the study were in the normal range at the start of the study and at the end (10 days after the training run). They were only outside the range after the $13-\mathrm{km}$ run.

Urobilinogen was significantly elevated $1 \mathrm{~h}$ and 1 day after the increased distance training run and returned to within the normal range thereafter as measured 4 days and 10 days after the training run (Table 3). Morphological changes following the increased distance training run are also shown in Table 3. Poikilocytosis was significantly elevated $1 \mathrm{~h}, 1$ day and 4 days following the training run as compared with pre-training values, while there was no significant change in reticulocytosis at any of the measurement times selected for this study.

\section{Discussion}

This study was designed to examine the effects of a typical change in endurance training, an increased distance run, on the haematological state of the non-competitive distance runner. Based on the information obtained (physiological, body composition measures, training and current competition status) and a comparison of this with high calibre distance runners, the subjects in this study can be described as a typical group of recreational runners. The great majority of people who run as a means of improving cardiorespiratory fitness and maintaining body composition, fall into this non-competitive recreational category; and yet, little if any haematological research has been carried out using them as study subjects. One of the reasons they are of interest, aside from their numbers, is that out of this group will come a number of dedicated and enthusiastic distance runners who will train harder and longer, eventually making the transition to a highly competitive state. An understanding of the acute haematological changes in the recreational runner may provide an insight into how the known haematological adaptations, both positive and negative, occur in the highly competitive distance runner.

It is known from research regarding the competitive distance runner, that regular prolonged exercise brings about diverse haematological responses and adaptations. Among the haematological responses in the high calibre distance runner are gastrointestinal bleeding 19 and an increased intravascular haemolysis ${ }^{8,10,20}$. Adaptations include beneficial effects such as dilutional pseudoanaemia ${ }^{21}$ and an increased red cell mass ${ }^{22}$ as well as a possible iron-deficient anaemic state ${ }^{23,24}$ which is detrimental to performance. The purpose of this study was to investigate whether or not a typical increase in daily training distance would increase intravascular haemolysis in the non-competitive, recreational distance runner.

Eichner $^{21}$ has suggested a diagnostic triad for footstrike haemolysis that includes subnormal haptoglobin concentration, mild reticulocytosis, and mild macrocytosis. Other researchers have noted increases in bilirubin, serum potassium and LDH, and decreases in red blood cell volume and haematocrit, to be indicators of increased intravascular haemolysis $^{20,25}$. Most researchers have used a transient decreased concentration of haemoglobin to identify 'sports anaemia'26, the primary cause of which has been attributed to intravascular haemolysis ${ }^{27}$. The athlete's state of hydration is an important consideration when deciding which of the criteria to use. Body weight has been shown to be a valid and reliable indicator of hydration state ${ }^{28}$. In the current study, mean body weight as measured 1 day after the run and compared to the pre-training run mean(s.d.) $(70.3(6.8)$ versus $70.6(7.3) \mathrm{kg}$ ) was not significantly lower $(P>0.01)$.

It can be concluded from the results of this study that intravascular haemolysis also occurs in the recreational runner. Evidence for this included significant 1-day decreases in haptoglobin, haemoglobin, red blood cell and haematocrit and the immediate post-training run increases in bilirubin, serum potassium and urobilinogen. Morphological evidence included significant increases in poikilocytosis as measured $1 \mathrm{~h}, 1$ day and 4 days after the increased distance training run, and increases in reticulocytosis and mean cell volume 4 days afterwards which were not significant. With the exception of haemoglobin, all of the observed significant changes following the increased distance training run returned to pre-training run levels by the tenth day after the run.

The increased intravascular haemolysis that occurred in this study with these recreational runners can be described as transitory and mild; transitory because of the non-significant variable differences observed on the tenth day after the training run as compared with pre-training values. Other studies using highly trained subjects have reported decreases in haemoglobin of up to $2.6 \mathrm{~g} \mathrm{dl}^{-1}$ (reference 8 ) and haptoglobin to be exhausted following marathon running ${ }^{29}$, while this study noted a mean drop of $30 \%$ in haptoglobin and only a modest $\left(0.6 \mathrm{~g} \mathrm{dl}^{-1}\right)$ decrease in haemoglobin. However, five subjects in the study exhibited a mean decrease of haemoglobin greater than $1.0 \mathrm{~g} \mathrm{dl}^{-1}$, with the greatest decrease in haemoglobin being $1.6 \mathrm{~g} \mathrm{dl}^{-1}$. The findings of this study with respect to haptoglobin and haemoglobin are similar to those reported recently for aerobic dance ${ }^{4}$.

In contrast to other research investigations of sports anaemia, this study suggests that intravascular haemolysis may be a relative phenomenon that occurs even in the recreational runner when adjustments to typical training distances are made. The results indicate that this transient condition is best assessed by immediate post-exercise bilirubin, serum potassium and urobilinogen determinations; and by 1-day post-exercise measurements of haptoglobin, haemoglobin and red blood cells. Since haemoglobin continued to be significantly decreased 4 days and 10 days after the increased distance training run, it might be advisable to moderate training for the next 
several days to ensure complete haematological recovery.

The increased intravascular haemolysis in the recreational runner may be a contributing stimulus for the beneficial cardiorespiratory endurance adaptation of erythrocythaemia or might even be important in bringing about an optimal haematological state for performance, which seems to be a borderline anaemic state $^{30}$. Further haematological research is needed regarding the repeated effects of such changes in training, including intensity as well as distance, over a longer period of training, and their relationship to performance.

\section{Acknowledgements}

The author wishes to thank Mary Lou Rodriguez for her preparation of the paper.

\section{References}

1 Eichner ER. Other medical considerations in prolonged exercise. In: Lamb DR, Murray R, eds. Perspectives in Exercise Science and Sports Medicine, vol 1: Prolonged Exercise. Indianapolis, Indiana, USA: Benchmark Press, 1988: 420.

2 Radomski MW, Sabiston BH, Isoard P. Development of 'sports anemia' in physically fit men after daily sustained submaximal exercise. Aviat Space Environ Med 1980; 51: 41-5.

3 Streeton JA. Traumatic haemoglobinuria caused by karate exercises. Lancet 1967; ii: 191-2.

4 Schwellnus NP, Penfold GK, Cilliers JF, Kuyl JM, van der Heever DP. Intravascular hemolysis in aerobic dancing: the role of floor surface and type of routine. Phys Sportsmed 1989; 17: 55-67.

5 Schmidt W, Maasen N, Trost F, Bowing D. Training induced effects on blood volume, erythrocyte turnover and hemoglobin oxygen binding properties. Eur J Appl Physiol 1988; 57: 490-8.

6 Casoni I, Borsetto C, Cavicchi A, Martinelli S, Conconi F. Reduced hemoglobin concentration and red cell hemoglobinization in Italian marathon and ultramarathon runners. Int $J$ Sports Med 1985; 6: 176-9.

7 O'Toole ML, Hiller WDB, Roalstad MS, Douglas PS. Hemolysis during triathlon races: its relation to race distance. Med Sci Sports Exerc 1988; 20: 272-5.

8 Dressendorfer, RH, Wade CW, Amsterdam EA. Development of pseudoanemia in marathon runners during a 20-day road race. JAMA 1981; 246: 1215-18.

9 Magazanik A, Weinstein Y, Dlin RA, Derin M, Schwartzman $S$, Allabouf $D$. Iron deficiency caused by 7 weeks of intensive physical exercise. Eur J Appl Physiol 1988; 57: 198-202.

10 Dufaux B, Hoederath A, Streitberger I, Hollmann W Assmann G. Serum ferritin, transferrin, haptoglobin, and iron in middle- and long-distance runners, elite rowers, and professional racing cyclists. Int J Sports Med 1981; 2: 43-6.

11 Zuti WB, Golding LA. Equations for estimating percent fat and body density of active adult males. Med Sci Sports 1973; 5: 262-70.

12 Rao J, Pelavin MH, Morgenstern S. SMAC high-speed continuous-flow, ion-selective electrodes for sodium and potassium: theory and design. In: Advances in automated analysis, technicon international congress 1972, Vol. 1: Clinical Chemistry Methods, New York, USA: mediad, 1973: 33-6.

13 Morgenstern S, Flor R, Kessler G, Klein B. Automated determination of NAD coupled enzymes, determination of lactic dehydrogenase. Anal Biochem 1965; 13: 149-61.

14 Gambino SR, Schreiber $\mathrm{H}$. The measurement and fractionation of bilirubin on the autoanalyzer by the method of Jendrassik and Graf. In: Automation in analytical chemistry, technicon symposia, New York, USA: mediad, 1965: 42-6.

15 Dayton CM. The Design of Educational Experiments. New York, USA: McGraw-Hill, 1970: 245.

16 Pollock ML, Wilmore JH, Fox SM. Health and fitness through physical activity. New York, USA: John Wiley and Sons, 1978: 266-7.

17 Costill DL, Winrow E. Maximal oxygen intake among marathon runners. Arch Phys Med Rehab 1970; 51: 317-20.

18 Ramsbottom R, Williams C, Boobis L, Freeman W. Aerobic fitness and running performance of male and female recreational runners. I Sport Sci 1989; 7: 9-20.

19 Fisher RL, McMahon LF, Ryan MJ, Larson D, Brand, M Gastrointestinal bleeding in competitive runners. Dig Dis Sci 1986; 31: 1226-8.

20 Lindemann $R$, Ekanger R, Opstad PK, Nummestad $M$, Ljosland $R$. Hematological changes in normal men during prolonged severe exercise. Am Corr Ther J 1978; 32: 107-11.

21 Eichner ER. The anemias of athletes. Phys Sportsmed 1986; 14: 122-30.

22 Brotherhood J, Brozovic B, Pugh LGC. Haematological status of middle- and long-distance runners. Clin Sci Mol Med 1975; 48: 139-45.

23 Hunding A, Jordal R, Paulev PE. Runner's anaemia and iron deficiency. Acta Med Scand 1981; 209: 315-18.

24 Ehn L, Carlmark B, Hoglund S. Iron status in athletes involved in intense physical activity. Med Sci Sports Exerc 1980; 12: 61-4.

25 Wolf PL, Lott JA, Nitti GJ, Bookstein R. Changes in serum enzymes, lactate, and haptoglobin following acute physical stress in international-class athletes. Clin Biochem 1987; 20: 73-7.

26 Pate RR. Sports anemia: a review of the current research literature. Phys Sportsmed 1983; 11: 115-31.

27 Yoshimura $\mathrm{H}$. Anemia during physical training (sports anemia). Nutr Rev 1970; 28: 251-3.

28 Young AJ, Sawka MN, Dennis RC, Pandolf KB, Valeri CR. Blood volume variability due to anthropometric factors and aerobic fitness. Med Sci Sports Exerc 1990; 22: S135.

29 Eichner ER. Runner's macrocytosis: a clue to footstrike hemolysis. Runner's anemia as a benefit versus runner's hemolysis as a detriment. Am J Med 1985; 78: 321-5.

30 Crowell JW, Smith EE. Determinant of the optimal hematocrit. J Appl Physiol 1967; 22: 501-4. 